\title{
Pinpoint and Synergistic Trading Strategies of Candlesticks
}

\author{
Yung-Ming Shiu \\ Department of Business Administration, National Cheng Kung University \\ No.1, University Road, Tainan City 701, Taiwan (R.O.C.) \\ Tel: 886-6-275-7575 ext.53330Ｅ-mail: yungming@mail.ncku.edu.tw \\ Tsung-Hsun Lu (corresponding author) \\ Department of Business Administration, National Cheng Kung University \\ No.1, University Road, Tainan City 701, Taiwan (R.O.C.) \\ Tel: 886-6-208-0137_E-mail: r4895107@mail.ncku.edu.tw
}

\begin{abstract}
The candlestick trading strategy is a very popular technical method to convey the growth and decline of the demand and supply in the financial market. In this paper, we aim to investigate the predictive power of the candlestick two-day patterns, and to determine the key factors to improve performance. The data set of this study includes daily opening, high, low, and closing prices, and daily volumes of all electronic securities in the Taiwan Stock Exchange between 1998 and 2007.

The result of this paper indicates that the harami pattern can obtain information about short-term price movements derived from the demand and supply in Taiwan stock market, because the performances from the harami signals are significantly positive overwhelmingly. The main contribution of this study is that it improves these trading strategies with three confirmation factors, that is, the open of the day after a reversal pattern, the changes of real bodies between two days, and the changes in volume. In addition, this is the first time that candlesticks research has employed the Quantile Regression Model.
\end{abstract}

Keywords: Candlestick, Reversal pattern, The QR model, Technical analysis

\section{Introduction}

Since Steve Nison introduced this new charting technique to the Western world from Japan in 1970s (Nison, 1991), this analysis avenue is highly recommended by financial traders and investors around the world. Practitioners prefer to make money without risk, but academicians' interest is in finding out the context of price developments. In other words, the fundamental basis and the statistical significance behind the patterns are often subordinated by the devotees of the technicians. It is a difficult task between serving the academician and serving the technician. In the past, the academician loved to pick on the technician (Malkiel, 1981). As the rising of behavioral finance, scholars pay more attention to technical analysis, because behavioral finance and technical analysis call the rationality of investors in question. Kahneman \& Tversky (1979) address the reflection effect, heuristic-driven bias in their prospect theory to reveal the irrationality of investors as they faced gain and loss. Even so, technicians convert the mental emotion of investors into chart patterns in particular time intervals, and reveal the real fear and greed of the investors. Thus positive feedback rules (De Long et. al., 1990) reveal trend-chasing in price movement and anchoring (Kahneman \& Tversky, 1979) seems explain the support and resistance trading rules in technical analysis.

The procedures of technicians violate the efficient market hypothesis which argues that advantages would diminish and trading methods would self-destruct when it would soon be used by its adherents. So the value of charting analysis has been neglected by the academic palace in the past. Thanks to behavioral finance, this is changing. The academician discusses charting analysis gradually. Practitioners divide technical analysis into two groups-visual patterns in charts and mathematical indicators by calculating. Most of the empirical research related to technical analysis revolves around visual patterns. For instance, Levy (1971) reviews thirty-two patterns of stock prices and examines the excess returns. Brock, Lakonishok \& LeBaron (1992) treat support and resistance as trading rules. Their results provide strong support for technical strategies. In addition, Osler (1997) utilizes head and shoulders patterns as a filter to test the significance of abnormal returns of stock prices.

The candlestick technique is also a visual patterns approach. It was created in Japan in the 18th century by a man named Munehisa Honma (Nison, 1991; Caginalp \& Laurent, 1998). A few centuries latter, Steve Nison introduced it to the Western world where it has been increasingly popular (Nison, 1991). This method reflects more information, especially regarding the psychology in the market, than others. As for recent research about candlesticks, Fock, Klein, \& Zewergel (2005) use five-minute data from the index futures on German stock index (DAX) and the bond futures on German government bonds (FGBL) to test candlesticks against a benchmark built from randomization. Other studies employ daily data, for instance, Caginalp \& Laurent (1998) examine eight three-day reversal patterns for all S\&P 500 stocks over 1992-1996. Marshall, Young, \& Rose (2006) test 35 stocks on the Dow Jones Industrial Average over the period 1992-2001. After this, Marshall, Young, \& Cahan (2006) use the same method to study the Japanese stock market. Their results provide depressing findings for candlestick trading strategies. In addition, Goo, 
Chen, \& Chang (2007) utilize the daily data of 25 component stocks in the Taiwan Top 50 Tracker Fund and Taiwan Mid-Cap 100 Tracker Fund over the period from 1997 to 2006, and found strong support for candlestick techniques. None of the above takes trading volume or positions into consideration, which are considered to confirm the forecasting power of candlesticks in practice. The motivation for this study has been developed.

Candlestick charts have more advantages for research than other technical analysis methods. They have more precise definitions, the time intervals are fixed and its signals are well-deploying (Caginalp \& Laurent, 1998). Because of the growth in behavioral finance in recent years, it has been found that emotional and mental reactions are important decisive factors in financial market behavior. Its findings correspond with that of candlesticks which reveal the dark forces of the demand and supply on financial markets by tracking daily price movements. By considering statistical analysis, charting analysis is able to offer objectivity in financial markets, and by trading regularly, the candlestick pattern is consistently one of the best strategies for investors (Caginalp \& Laurent, 1998).

Candlestick reversal patterns are notable when they occur in high-price areas or in low-price areas (Nison, 1991; Pring, 2002). Besides, trading volume always plays an important role for measuring popularity and reveals the aspiration of "accumulation" or "distribution". Thus, this study takes the changes of volume patterns into consideration. This task is distinct from previous research which combined mathematical indicators (Fock et al., 2005) or implemented stop-loss strategies (Goo et al., 2007). The key contribution of this paper is looking into the improvement of trading strategies using candlesticks by three criteria: the open of the day after the pattern, the gap of the two real bodies, and the change in volume. This task has not done in any previous study. Specifically, we employ quantile regression (QR hereafter) model to test the effect of the three criteria described above. To the best of our knowledge, this is the first research to use QR model on technical analysis methods.

This paper reveals that the returns of the candlesticks strategies are related to the three factors, the open of the day after the pattern, the real body of the candlestick, and the change in volume. The harami pattern is just best strategies of those tested in this paper for investors in Taiwan stock market.

The rest of this paper is structured as follows. Section 2 describes the data and methodology. Section 3 presents the QR model. Section 4 discusses the empirical results. Finally, concluding remarks are in section 5.

\section{Data Collection and Methodology}

\subsection{Data}

The data of this paper consists of daily prices and volumes for 69 electronic securities as posted by the Taiwan Stock Exchange. The time period covers ten years from 1998 to 2007. The data include four essential prices for candlesticks: opening, high, low, and closing prices.

\subsection{Pattern Definitions}

A single candlestick line includes information on the opening, high, low, and closing prices in a particular time period. The range between the opening and closing prices is called the real body. If the real body is white, it means that the closing price was higher than the opening price, and vice versa. The lines above and below the real body are called the shadows. Candlesticks are more used by daily data than intraday data (Nison, 1991). Presumably this is because investor reaction needs some time to be incubated. Popular daily candlestick patterns include single lines, two-day patterns, and three-day patterns. Several consecutive single lines can combine to form one pattern divided into continuation and reversal patterns. Continuation patterns imply that the previous trend will continue, and reversal patterns hint that the direction of price will change. In general, investors pay more attention to reversal patterns, because they always change the inertial trend. In this paper, we consider three bullish patterns and three bearish patterns, and they are all combined with two single lines (shown in Fig.1).

\subsection{Methodology}

The first arrangement of defining reversal patterns is identifying what is an uptrend or a downtrend. We employ a five-day moving average according to Caginalp \& Laurent (1998). And the moving average on day $\mathrm{t}$ is defined by:

$$
M A_{5}(t)=\frac{C(t-4)+C(t-3)+C(t-2)+C(t-1)+C(t)}{5}
$$

Where $\mathrm{C}(\mathrm{t})$ is the closing price on day $\mathrm{t}$.

An uptrend on day $t$ is defined by:

$M A_{5}(t-6)<M A_{5}(t-5)<\cdots<M A_{5}(t-1)<M A_{5}(t)$

On the contrary, a downtrend on day $\mathrm{t}$ is defined by:

$M A_{5}(t-6)>M A_{5}(t-5)>\cdots>M A_{5}(t-1)>M A_{5}(t)$

Next, we must define how to measure the returns of the profit by the candlestick reversal patterns. This paper measures profits based on three rules. First, the beginning of the measuring is at the opening price on the day following a reversal pattern. Secondly, the end of the measuring is at the closing price on each holding day. Thirdly, positions are held for one to five days. Short-term candlestick strategies are used (Nison, 1991; Morris, 1995), and 
opposite patterns occur for more than five holding days. So we adopt the frame of five days.

In this study, we will use quantile regression developed by Heckman (1979) to test the predictive power of candlestick reversal patterns. In comparison with the ordinary least square method, the QR model offers a relatively rich description of the conditional mean for extreme cases in the samples.

\section{QR Model}

There is no consistent conclusion for the predictive power of candlesticks in previous findings. This paper attempts to improve candlestick trading rules on an even more pragmatic basis. To begin with, this study examines the returns of six reversal pattern of candlesticks without restriction. Then, the "confirmations" of candlesticks are part and parcel (Pring, 2002), and we inspect three criteria for modifying the predictive power of the six reversal patterns.

First, the open of the day after the pattern is very important. For example, if the open of the day after a bearish reversal pattern is higher than the close of the last day, the buyer will slack off slightly, and the device of the shorter will be held back, and vice versa. We define a variable named $\triangle O P E N$ to test this effect.

Secondly, we take the real body of the candlestick into consideration. The gap of the two real bodies of one reversal pattern exhibits well-matched strength. In harami, the smaller the second real body, the more potent the pattern, because the smaller the real body, the greater the ambivalence and the more likely a trend reversal will occur (Nison, 1991). In other patterns, like the piercing, if the two real bodies are both large, the reliability of this pattern will increase since the bears depleted their energy. Thus, the smaller the gap of the two real bodies of the piercing is the better. We name this variable as $\triangle R B$.

Thirdly, volume is a measure of demand and supply, and a confirmation of price trends. Changes of volume patterns will be the omen of the reversal of a trend. We name this variable as $\Delta \ln Q$. Above of all, these three variables are potential triggers for the pivot point of candlesticks.

By using six reversal patterns and holding days, a QR model is applied to discuss whether these three variables can significantly affect the rate of return.

\section{Empirical results}

\subsection{Candlesticks statistics}

In Table 1, the mean rates of return for each candlestick reversal pattern on each holding day are presented. It shows that the bullish harami are positively significant on holding four days and five days, the dark-cloud cover is negatively significant on holding five days, the bearish engulfing are negatively significant on holding three days to five days, and the bearish harami are positively significant on holding one day to five days. They are negative results except the harami. We review three criteria for modifying the predictive power of the six reversal patterns as follows.

\subsection{QR statistics}

\subsubsection{Piercing}

In Tables 2 to 6 , in spite of holding days, the $\triangle O P E N$ coefficients are significantly negative. However, the other two variables are both insignificant. This result indicates that this pattern was generally influenced by the open after the pattern. By the meaning of demand and supply, the trend is in a falling market originally, and the second day of this pattern opens sharply lower under the low of the prior day. This atmosphere strengthens the confidence of the bears, but good times don't last long. Subsequently, prices push higher above the mid-point of the prior day's real body. This peripeteia will either make the bears worry about their positions, or mean that it is time to finish the bottom. Accordingly, if the next day after this pattern opens lower via a gap, the bears will be allured to bear-cover, and thus it will stimulate a surge for an uptrend.

\subsubsection{Bullish Engulfing}

Tables 7 to 11 present QR estimates of the bullish engulfing. The $\triangle O P E N$ coefficients are significantly negative on holding for one day in this pattern. But on holding for three to five days, the $\triangle R B$ coefficients are significantly positive. When the quantiles develop, the $\triangle R B$ coefficient increases.

\subsubsection{Bullish Harami}

In Tables 12 to 16 , three variables, i.e. $\triangle O P E N, \triangle R B$ and $\triangle \ln Q$, are almost insignificant, and the few existing significances are decentralizing in some holding days and quantiles. Only the $\triangle \ln Q$ coefficients are significantly positive on holding for one day in the $90^{\text {th }}$ quantile at $1 \%$ (see Table 12). This pattern is considered a brake in the trend, because the second line of the pattern requires a narrow range built by the open and the close. This is just a lull before it changes and the trading area of the second day forming this pattern reduces, so it needs enormous popularity to reverse.

\subsubsection{Dark-Cloud Cover}

The dark-cloud cover is influenced by the three main variables in this study. The variable $\triangle O P E N$ is significantly positive on holding for one day and two days (see Table 17 and 18), and the variable $\triangle R B$ is negative on holding for tow days to four days in high return areas (see Table 18 and 19), that is quantiles are larger than the $50^{\text {th }}$. The 
variable $\triangle \ln Q$ is significantly negative on holding for one day except at the $90^{\text {th }}$ quantiles. This reveals that the open of the day following this pattern is higher, and the trading areas of the two days formed this pattern are both large, and the volume of the second day that formed this pattern is smaller signifying that this pattern enhances profits. The rationale behind this pattern is abundantly clear. Originally, the open of the second day is above the prior day's high, thus the atmosphere of the market abounds with contentment, however the end of the market closes near the low of the prior day, at least penetrating it by half. In such a scenario, the bulls lost heart, and the control of the market has moved from the bulls to the bears. This pattern may be regarded as the last flounce of the bulls with spent force.

\subsubsection{Bearish Engulfing}

In Tables 22 to 26 and in their low return areas, the variable $\triangle O P E N$ is extremely significantly positive. In general, when the quantiles develop, the $\triangle O P E N$ coefficient decreases. In high return areas, the coefficients are even negative. This means that the day after this pattern opens low signifies a reinforcing condition. This pattern occurred after a uptrend, and all potential buyers have already jumped into the market, resulting in a price rise that is difficult for the following buyers, whereas swarmming with shorting force from profitable sellers along the uptrend.

\subsubsection{Bearish Harami}

In Tables 27 to 31 , the variables $\triangle O P E N$ and $\triangle R B$ are significantly positive in high return areas. The greater $\triangle R B$, the greater the return becomes. Because this pattern essentially is a wait-and-see situation, it shows the doughy bears when $\triangle R B$ is small. It's worth mentioning that these three variables are insignificant in low return areas whereas $\triangle O P E N$ and $\triangle R B$ are extremely significant in high return areas on holding for three days to five days.

In a nutshell, if investors want to use the bearish harami for trading, they have to notice the problems which are the gap of the two real bodies of the pattern and the open of the day following the pattern. Furthermore, in regards to the trading volume aspect, it reveals less significance than the other two factors in high return areas, because the change from uptrend to downtrend price has its own gravity, like Free-Falling Objects. This pattern is very similar to the Western inside day. From supply and demand aspect, in the uptrend, a white line occurs, and on the following day opens lower and the price ambulates in a limited boundary. At the same time, no one buy any further, everything just stops and the market "catches its breath". The harami just like the brake of the trend and the condition should be stopped in the while and the price will move in a very small range.

\section{Conclusion and Suggestion}

Our evidence suggests that the harami pattern is just the best trading rule in six candlestick reversal patterns tested for this study in Taiwan stock market, because this strategy is more frequent and most trustworthy according to our results. The results of the mean rate of returns are not significantly positive, but they have a relationship with the confirmative criteria, are the open after the pattern, the gap of the two real bodies, and the volume change in the second day of the pattern.

To the best of our knowledge, this study is the first to test the predictive power of candlestick reversal patterns with the Quantile Regression Model and address the problem of confirmative factors. The other contribution of this paper is that it takes trading volume and positions into consideration, which be said to the confirmation of candlesticks. It is the key to the optimization of the oldest form of technical analysis, the candlestick trading strategy. In the previous studies, Fock et al. (2005) use the indicators to improve the performance of candles, and Goo's et al. (2007) take stop-loss strategies into consideration. Both of their methods improved the candlestick strategies. We optimize the candlestick trading strategies by other means.

When evaluating the effectiveness of a reversal pattern, another key factor should be considered, the support or resistance level. This is because technical analysts believe that investors are willing to sell at the peak and to buy at the bottom (Brock et al., 1992). Therefore, future studies should address this topic with the candlestick trading strategy.

\section{References}

Caginalp, G. \& H. Laurent. (1998). The Predictive Power of Price Patterns. Applied Mathematical Finance, 5, 181-205.

Brock, W., Lakonishok, J., \& LeBaron, B. (1992). Simple Technical Trading Rules and Stochastic Properties of Stock Returns. Journal of Finance, 47, 1731-1764.

De Long, B., A. Shleifer, L. Summers \& R. Waldmann. (1990). Positive Feedback Investment Strategies and destabilizing Rational Speculation. Journal of Finance, 45, 379-395.

Fock, J.H., C. Klein \& B. Zwergel. (2005). Performance of Candlestick Analysis on Intraday Futures Data. Journal of Futures Markets, 13, 28-40.

Heckman, J. (1979). Sample Selection Bias as a Specification Error. Econometrica, 47, 153-161.

Kahneman, D. \& Tversky, A. (1979). Prospect theory: an analysis of decision under risk. Econometrica, 47, 263-291.

Levy, R. (1971). The Predictive Significance of Five-Point Chart Patterns. The Journal of Business, 44, 316-323. 
Malkiel, B. (1981). A Random Walk Down Wall Street. (2rd ed.). New York: Norton.

Marshall, B.R., M.R. Young \& L.C. Rose (2006). Candlestick Technical Trading Strategies: Can They Create Value for Investors? Journal of Banking \& Finance, 30, 2303-2323.

Marshall, B.R., M.R. Young \& R. Cahan (2006). Are Candlestick Technical Trading Strategies Profitable in the Japanese Equity Market? Review of Quantitative Finance \& Accounting, 31, 191-207.

Morris, G.L. (1995). Candlestick Charting Explained: Time Techniques for Trading Stocks and Futures.(2rd ed.). New York: McGraw-Hill.

Nison, S. (1991). Japanese Candlestick Charting Techniques. New York Institute of Finance.

Osler, C. L. (1997). Technical Trading as a Source of Market Irrationality: The Head-Shoulders Pattern in Foreign Exchange. Federal Reserve Bank of New York.

Pring, M. (2002). Candlesticks Explained. New York: McGraw-Hill.

Goo, Y., Chen, D. \& Chang, Y. (2007). The Application of Japanese Candlestick Trading Strategies in Taiwan. Investment Management and Financial Innovations, 4, 49-71.

Table1. The average returns of six candlestick reversal patterns

\begin{tabular}{|lccccc|}
\hline & \multicolumn{5}{c}{ Holding-day } \\
\cline { 2 - 6 } & 1 & 2 & 3 & 4 & 5 \\
\hline Piercing & $0.19 \%$ & $1.55 \%$ & $1.51 \%$ & $1.78 \%$ & $1.53 \%$ \\
\hline Bullish Engulfing & $-0.11 \%$ & $-0.09 \%$ & $-0.14 \%$ & $-0.17 \%$ & $-0.02 \%$ \\
\hline Bullish Harami & $-0.03 \%$ & $-0.08 \%$ & $0.47 \%$ & $2.31 \% *$ & $5.78 \% \%^{* *}$ \\
\hline Dark-Cloud Cover & $-0.37 \%$ & $-0.50 \%$ & $-0.64 \%$ & $-0.83 \%$ & $-1.14 \%^{*}$ \\
\hline Bearish Engulfing & $0.02 \%$ & $-0.15 \%$ & $-0.38 \%^{* * *}$ & $-0.57 \%^{* * *}$ & $-0.87 \%^{* * *}$ \\
\hline Bearish Harami & $0.42 \%^{* * *}$ & $0.47 \%^{* * *}$ & $0.70 \%^{* * *}$ & $0.7 \%^{* * * *}$ & $0.54 \%^{* * *}$ \\
\hline
\end{tabular}

Note: $* *$ is significant at the $1 \%$ level; $* *$ is significant at the $5 \%$ level; * is significant at the $10 \%$ level.

Table 2. Estimation Results for the Quantile Regression—Piercing—holding for 1 day

\begin{tabular}{|llllllll|}
\hline Variables & $5^{\text {th }}$ & $10^{\text {th }}$ & $25^{\text {th }}$ & $50^{\text {th }}$ & $75^{\text {th }}$ & $90^{\text {th }}$ & $95^{\text {th }}$ \\
\hline \multirow{2}{*}{$\triangle$ OPEN } & -0.1967 & $-0.2987^{* * *}$ & -0.1441 & -0.0241 & -0.1343 & $-0.4928^{* * *}$ & $-0.7416^{* * *}$ \\
& $(0.2790)$ & $(<0.0001)$ & $(0.1070)$ & $(0.7810)$ & $(0.5040)$ & $(0.0090)$ & $(<0.0001)$ \\
\hline \multirow{2}{*}{$\triangle R B$} & -0.0136 & -0.0051 & -0.0017 & -0.0043 & -0.0122 & -0.0043 & 0.0009 \\
& $(0.2360)$ & $(0.4030)$ & $(0.7160)$ & $(0.2940)$ & $(0.1530)$ & $(0.6500)$ & $(0.9230)$ \\
\hline \multirow{2}{*}{$\triangle \ln Q$} & -0.0045 & 0.0010 & -0.0009 & 0.0030 & $0.0130^{* *}$ & 0.0062 & 0.0023 \\
& $(0.4630)$ & $(0.7630)$ & $(0.7890)$ & $(0.3920)$ & $(0.0350)$ & $(0.4070)$ & $(0.8160)$ \\
\hline
\end{tabular}

Note: $* *$ is significant at the $1 \%$ level; $* *$ is significant at the $5 \%$ level; * is significant at the $10 \%$ level. The number of observations is 247. The upper numbers are the coefficient of the quantile regression and the p-values are in the parentheses.

Table 3. Estimation Results for the Quantile Regression—Piercing—holding for 2 days

\begin{tabular}{|llllllll|}
\hline Variables & $5^{\text {th }}$ & $10^{\text {th }}$ & $25^{\text {th }}$ & $50^{\text {th }}$ & $75^{\text {th }}$ & $90^{\text {th }}$ & $95^{\text {th }}$ \\
\hline \multirow{2}{*}{$\triangle$ OPEN } & $-0.7404^{* * *}$ & $-0.4610^{* *}$ & $-0.4102^{* *}$ & -0.1173 & -0.0035 & -0.2197 & -0.5448 \\
& $(0.0050)$ & $(0.0500)$ & $(0.0200)$ & $(0.4690)$ & $(0.9880)$ & $(0.5360)$ & $(0.5640)$ \\
\hline \multirow{2}{*}{$\triangle R B$} & $0.0236^{*}$ & 0.0135 & -0.0028 & -0.0055 & -0.0026 & 0.0165 & 0.0010 \\
& $(0.0990)$ & $(0.1960)$ & $(0.7470)$ & $(0.4960)$ & $(0.7930)$ & $(0.2050)$ & $(0.9640)$ \\
\hline \multirow{2}{*}{$\triangle \ln Q$} & -0.0106 & -0.0095 & -0.0032 & -0.0005 & 0.0071 & 0.0204 & 0.0154 \\
& $(0.3760)$ & $(0.2630)$ & $(0.6020)$ & $(0.9350)$ & $(0.5160)$ & $(0.1310)$ & $(0.6410)$ \\
\hline
\end{tabular}

Note: $* * *$ is significant at the $1 \%$ level; $* *$ is significant at the $5 \%$ level; * is significant at the $10 \%$ level. The number of observations is 247 . The upper numbers are the coefficient of the quantile regression and the p-values are in the parentheses.

Table 4. Estimation Results for the Quantile Regression—Piercing—holding for 3 days

\begin{tabular}{|llllllll|}
\hline Variables & $5^{\text {th }}$ & $10^{\text {th }}$ & $25^{\text {th }}$ & $50^{\text {th }}$ & $75^{\text {th }}$ & $90^{\text {th }}$ & $95^{\text {th }}$ \\
\hline \multirow{2}{*}{$\triangle$ OPEN } & -0.2200 & -0.2834 & -0.3499 & $-0.3893^{* *}$ & -0.0305 & -0.1762 & -0.0258 \\
& $(0.7070)$ & $(0.4320)$ & $(0.1830)$ & $(0.0390)$ & $(0.9090)$ & $(0.7170)$ & $(0.9820)$ \\
\hline \multirow{2}{*}{$\triangle R B$} & 0.0135 & 0.0024 & 0.0029 & 0.0001 & 0.0053 & 0.0060 & -0.0114 \\
& $(0.4700)$ & $(0.8980)$ & $(0.8160)$ & $(0.9880)$ & $(0.6810)$ & $(0.7200)$ & $(0.7630)$ \\
\hline \multirow{2}{*}{$\triangle \ln Q$} & -0.0192 & -0.0142 & -0.0110 & -0.0150 & 0.0062 & 0.0329 & 0.0318 \\
& $(0.2160)$ & $(0.2350)$ & $(0.2440)$ & $(0.0440)$ & $(0.6100)$ & $(0.2890)$ & $(0.3590)$ \\
\hline
\end{tabular}

Note: *** is significant at the $1 \%$ level; $* *$ is significant at the $5 \%$ level; * is significant at the $10 \%$ level. The number of observations is 247 . The 
upper numbers are the coefficient of the quantile regression and the p-values are in the parentheses.

Table 5. Estimation Results for the Quantile Regression—Piercing—holding for 4 days

\begin{tabular}{|llllllll|}
\hline Variables & $5^{\text {th }}$ & $10^{\text {th }}$ & $25^{\text {th }}$ & $50^{\text {th }}$ & $75^{\text {th }}$ & $90^{\text {th }}$ & $95^{\text {th }}$ \\
\hline \multirow{2}{*}{$\triangle$ OPEN } & -0.3623 & 0.0987 & -0.1345 & $-0.2868^{*}$ & -0.1198 & -0.0114 & 0.1293 \\
& $(0.7360)$ & $(0.7790)$ & $(0.6470)$ & $(0.0980)$ & $(0.7120)$ & $(0.9810)$ & $(0.9060)$ \\
\hline \multirow{2}{*}{$\triangle R B$} & 0.0120 & -0.0036 & 0.0031 & 0.0036 & $0.0333^{*}$ & 0.0220 & 0.0130 \\
& $(0.7000)$ & $(0.8550)$ & $(0.8490)$ & $(0.6800)$ & $(0.0660)$ & $(0.3970)$ & $(0.8270)$ \\
\hline \multirow{2}{*}{$\triangle \ln Q$} & -0.0262 & -0.0115 & -0.0051 & $-0.0217^{* * *}$ & 0.0042 & 0.0401 & 0.0333 \\
& $(0.4320)$ & $(0.3410)$ & $(0.6490)$ & $(0.0020)$ & $(0.7940)$ & $(0.2620)$ & $(0.8170)$ \\
\hline
\end{tabular}

Note: $* * *$ is significant at the $1 \%$ level; $* *$ is significant at the $5 \%$ level; * is significant at the $10 \%$ level. The number of observations is 247 . The upper numbers are the coefficient of the quantile regression and the p-values are in the parentheses.

Table 6. Estimation Results for the Quantile Regression—Piercing—holding for 5 days

\begin{tabular}{|llllllll|}
\hline Variables & $5^{\text {th }}$ & $10^{\text {th }}$ & $25^{\text {th }}$ & $50^{\text {th }}$ & $75^{\text {th }}$ & $90^{\text {th }}$ & $95^{\text {th }}$ \\
\hline \multirow{2}{*}{$\triangle$ OPEN } & -0.6192 & -0.0125 & -0.0665 & -0.3091 & -0.0389 & -0.3418 & -0.1718 \\
& $(0.6210)$ & $(0.9770)$ & $(0.7860)$ & $(0.1520)$ & $(0.8740)$ & $(0.6510)$ & $(0.8910)$ \\
\hline \multirow{2}{*}{$\Delta R B$} & 0.0021 & -0.0035 & $0.0269^{*}$ & 0.0066 & 0.0104 & $0.0551^{*}$ & 0.0497 \\
& $(0.9740)$ & $(0.8610)$ & $(0.0630)$ & $(0.5430)$ & $(0.4220)$ & $(0.0510)$ & $(0.5580)$ \\
\hline \multirow{2}{*}{$\Delta \ln Q$} & 0.0100 & 0.0026 & -0.0161 & -0.0102 & -0.0040 & 0.0294 & 0.0528 \\
& $(0.8000)$ & $(0.8660)$ & $(0.1180)$ & $(0.2430)$ & $(0.7380)$ & $(0.5430)$ & $(0.5250)$ \\
\hline
\end{tabular}

Note: *** is significant at the $1 \%$ level; $* *$ is significant at the $5 \%$ level; * is significant at the $10 \%$ level. The number of observations is 247 . The upper numbers are the coefficient of the quantile regression and the p-values are in the parentheses.

Table 7. Estimation Results for the Quantile Regression-Bullish Engulfing-holding for 1 day

\begin{tabular}{|llllllll|}
\hline Variables & $5^{\text {th }}$ & $10^{\text {th }}$ & $25^{\text {th }}$ & $50^{\text {th }}$ & $75^{\text {th }}$ & $90^{\text {th }}$ & $95^{\text {th }}$ \\
\hline \multirow{2}{*}{$\Delta$ OPEN } & $-0.1422^{*}$ & -0.1061 & $-0.1585^{* *}$ & $-0.0962^{* * *}$ & $-0.1113^{*}$ & $-0.2596^{* * *}$ & $-0.7074^{* * *}$ \\
& $(0.0520)$ & $(0.2330)$ & $(0.0120)$ & $(0.0070)$ & $(0.0980)$ & $(0.0050)$ & $(<0.0001)$ \\
\hline \multirow{2}{*}{$\Delta R B$} & $>-0.0001$ & 0.0002 & -0.0001 & $0.0004^{* *}$ & $0.0006^{*}$ & 0.0003 & 0.0001 \\
& $(0.9930)$ & $(0.6010)$ & $(0.7540)$ & $(0.0480)$ & $(0.0680)$ & $(0.5490)$ & $(0.7770)$ \\
\hline \multirow{2}{*}{$\Delta \ln Q$} & -0.0027 & -0.0031 & -0.0019 & -0.0020 & $-0.0046^{*}$ & 0.0022 & -0.0009 \\
& $(0.4430)$ & $(0.2310)$ & $(0.3680)$ & $(0.1310)$ & $(0.0650)$ & $(0.5910)$ & $(0.7750)$ \\
\hline
\end{tabular}

Note: ${ }^{* *}$ is significant at the $1 \%$ level; $* *$ is significant at the $5 \%$ level; $*$ is significant at the $10 \%$ level. The number of observations is 1161 . The upper numbers are the coefficient of the quantile regression and the p-values are in the parentheses.

Table 8. Estimation Results for the Quantile Regression-Bullish Engulfing-holding for 2 days

\begin{tabular}{|llllllll|}
\hline Variables & $5^{\text {th }}$ & $10^{\text {th }}$ & $25^{\text {th }}$ & $50^{\text {th }}$ & $75^{\text {th }}$ & $90^{\text {th }}$ & $95^{\text {th }}$ \\
\hline \multirow{2}{*}{$\Delta$ OPEN } & 0.0600 & 0.1292 & $0.1130^{*}$ & -0.0423 & 0.1005 & 0.1355 & -0.1248 \\
& $(0.6630)$ & $(0.2850)$ & $(0.0930)$ & $(0.5260)$ & $(0.2760)$ & $(0.5640)$ & $(0.8190)$ \\
\hline \multirow{2}{*}{$\Delta R B$} & -0.0004 & -0.0003 & -0.0004 & 0.0002 & 0.0004 & $0.0017^{* *}$ & 0.0019 \\
& $(0.3910)$ & $(0.5840)$ & $(0.1540)$ & $(0.5900)$ & $(0.3620)$ & $(0.0340)$ & $(0.2080)$ \\
\hline \multirow{2}{*}{$\Delta \ln Q$} & 0.0021 & -0.0023 & -0.0034 & -0.0059 & $-0.0046^{*}$ & 0.0017 & 0.0034 \\
& $(0.7450)$ & $(0.5630)$ & $(0.1360)$ & $(0.0160)$ & $(0.0980)$ & $(0.7700)$ & $(0.7750)$ \\
\hline
\end{tabular}

Note: ${ }^{* *}$ is significant at the $1 \%$ level; ${ }^{* *}$ is significant at the $5 \%$ level; $*$ is significant at the $10 \%$ level. The number of observations is 1161 . The upper numbers are the coefficient of the quantile regression and the p-values are in the parentheses.

Table 9. Estimation Results for the Quantile Regression—Bullish Engulfing—holding for 3 days

\begin{tabular}{|llllllll|}
\hline Variables & $5^{\text {th }}$ & $10^{\text {th }}$ & $25^{\text {th }}$ & $50^{\text {th }}$ & $75^{\text {th }}$ & $90^{\text {th }}$ & $95^{\text {th }}$ \\
\hline \multirow{2}{*}{$\Delta$ OPEN } & $0.3777^{* *}$ & $0.3918^{* * *}$ & 0.1457 & -0.0403 & 0.1388 & -0.0666 & -0.3957 \\
& $(0.0430)$ & $(0.0090)$ & $(0.1410)$ & $(0.6310)$ & $(0.2090)$ & $(0.8370)$ & $(0.5200)$ \\
\hline \multirow{2}{*}{$\Delta R B$} & -0.0009 & -0.0014 & -0.0001 & 0.0006 & $0.0010^{*}$ & $0.0027^{* *}$ & $0.0045^{* * *}$ \\
& $(0.3550)$ & $(0.1330)$ & $(0.8000)$ & $(0.1150)$ & $(0.0510)$ & $(0.0240)$ & $(0.0020)$ \\
\hline \multirow{2}{*}{$\Delta \ln Q$} & -0.0031 & -0.0090 & $-0.0093^{* *}$ & $-0.0052^{*}$ & -0.0040 & -0.0079 & -0.0098 \\
& $(0.6950)$ & $(0.1760)$ & $(0.0110)$ & $(0.0910)$ & $(0.2540)$ & $(0.3340)$ & $(0.3970)$ \\
\hline
\end{tabular}

Note: *** is significant at the $1 \%$ level; ** is significant at the $5 \%$ level; * is significant at the $10 \%$ level. The number of observations is 1161 . The upper numbers are the coefficient of the quantile regression and the p-values are in the parentheses. 
Table 10. Estimation Results for the Quantile Regression—Bullish Engulfing—holding for 4 days

\begin{tabular}{|llllllll|}
\hline Variables & $5^{\text {th }}$ & $10^{\text {th }}$ & $25^{\text {th }}$ & $50^{\text {th }}$ & $75^{\text {th }}$ & $90^{\text {th }}$ & $95^{\text {th }}$ \\
\hline \multirow{2}{*}{$\triangle O P E N$} & $0.4533^{*}$ & $0.3014^{*}$ & $0.2015^{*}$ & 0.1313 & 0.0877 & -0.0288 & -0.2408 \\
& $(0.0730)$ & $(0.0890)$ & $(0.0710)$ & $(0.1540)$ & $(0.4960)$ & $(0.9320)$ & $(0.7460)$ \\
\hline \multirow{2}{*}{$\Delta R B$} & -0.0023 & $-0.0028^{* *}$ & $-0.0010^{*}$ & 0.0004 & $0.0016^{* * *}$ & 0.0030 & $0.0054^{* * *}$ \\
& $(0.1510)$ & $(0.0150)$ & $(0.0600)$ & $(0.3600)$ & $(0.0060)$ & $(0.0140)$ & $(0.0040)$ \\
\hline \multirow{2}{*}{$\Delta \ln Q$} & 0.0033 & -0.0082 & -0.0035 & -0.0058 & -0.0045 & -0.0051 & 0.0001 \\
& $(0.7670)$ & $(0.2750)$ & $(0.3980)$ & $(0.0880)$ & $(0.2500)$ & $(0.5240)$ & $(0.9930)$ \\
\hline
\end{tabular}

Note: $* * *$ is significant at the $1 \%$ level; ** is significant at the $5 \%$ level; * is significant at the $10 \%$ level. The number of observations is 1161 . The upper numbers are the coefficient of the quantile regression and the p-values are in the parentheses.

Table 11. Estimation Results for the Quantile Regression-Bullish Engulfing—holding for 5 days

\begin{tabular}{|llllllll|}
\hline Variables & $5^{\text {th }}$ & $10^{\text {th }}$ & $25^{\text {th }}$ & $50^{\text {th }}$ & $75^{\text {th }}$ & $90^{\text {th }}$ & $95^{\text {th }}$ \\
\hline \multirow{2}{*}{$\Delta$ OPEN } & $0.8343^{* *}$ & $0.5809^{* *}$ & 0.1941 & 0.1427 & 0.0368 & -0.1155 & -0.5103 \\
& $(0.0180)$ & $(0.0200)$ & $(0.1110)$ & $(0.1400)$ & $(0.8150)$ & $(0.7320)$ & $(0.3190)$ \\
\hline \multirow{2}{*}{$\Delta R B$} & -0.0023 & $-0.0028^{* *}$ & $-0.0021^{* * *}$ & 0.0006 & $0.0012^{*}$ & $0.0032^{* * *}$ & $0.0063^{* * *}$ \\
& $(0.1820)$ & $(0.0250)$ & $(<0.0001)$ & $(0.2300)$ & $(0.0930)$ & $(0.0090)$ & $(0.0010)$ \\
\hline \multirow{2}{*}{$\Delta \ln Q$} & 0.0067 & 0.0004 & -0.0037 & -0.0027 & -0.0010 & 0.0085 & 0.0194 \\
& $(0.6400)$ & $(0.9670)$ & $(0.4430)$ & $(0.4440)$ & $(0.8340)$ & $(0.3140)$ & $(0.1800)$ \\
\hline
\end{tabular}

Note: $* * *$ is significant at the $1 \%$ level; ** is significant at the $5 \%$ level; * is significant at the $10 \%$ level. The number of observations is 1161 . The upper numbers are the coefficient of the quantile regression and the p-values are in the parentheses.

Table 12. Estimation Results for the Quantile Regression—Bullish Harami—-holding for 1 day

\begin{tabular}{|llllllll|}
\hline Variables & $5^{\text {th }}$ & $10^{\text {th }}$ & $25^{\text {th }}$ & $50^{\text {th }}$ & $75^{\text {th }}$ & $90^{\text {th }}$ & $95^{\text {th }}$ \\
\hline \multirow{2}{*}{$\Delta$ OPEN } & 0.0084 & -0.0362 & $-0.1383^{* * *}$ & -0.0099 & 0.1039 & -0.0942 & -0.1061 \\
& $(0.9460)$ & $(0.7110)$ & $(0.0060)$ & $(0.8250)$ & $(0.2490)$ & $(0.3730)$ & $(0.2340)$ \\
\hline \multirow{2}{*}{$\Delta R B$} & 0.0035 & 0.0035 & -0.0035 & -0.0024 & -0.0023 & -0.0061 & 0.0021 \\
& $(0.6340)$ & $(0.5690)$ & $(0.2340)$ & $(0.3660)$ & $(0.6420)$ & $(0.3660)$ & $(0.7760)$ \\
\hline \multirow{2}{*}{$\Delta \ln Q$} & -0.0025 & -0.0021 & 0.0016 & 0.0018 & $0.0054^{*}$ & $0.0141^{* * *}$ & $0.0065^{*}$ \\
& $(0.4780)$ & $(0.5020)$ & $(0.3180)$ & $(0.2280)$ & $(0.0640)$ & $(<0.0001)$ & $(0.0710)$ \\
\hline
\end{tabular}

Note: *** is significant at the $1 \%$ level; $* *$ is significant at the $5 \%$ level; * is significant at the $10 \%$ level. The number of observations is 1291 . The upper numbers are the coefficient of the quantile regression and the p-values are in the parentheses.

Table 13. Estimation Results for the Quantile Regression—Bullish Harami-holding for 2 days

\begin{tabular}{|llllllll|}
\hline Variables & $5^{\text {th }}$ & $10^{\text {th }}$ & $25^{\text {th }}$ & $50^{\text {th }}$ & $75^{\text {th }}$ & $90^{\text {th }}$ & $95^{\text {th }}$ \\
\hline \multirow{2}{*}{$\Delta$ OPEN } & 0.0941 & 0.0466 & -0.0252 & -0.0708 & -0.0861 & 0.1476 & 0.0418 \\
& $(0.5610)$ & $(0.7440)$ & $(0.8060)$ & $(0.1770)$ & $(0.4630)$ & $(0.5430)$ & $(0.9270)$ \\
\hline \multirow{2}{*}{$\Delta R B$} & $0.0226^{*}$ & $0.0169^{*}$ & 0.0032 & 0.0001 & -0.0057 & -0.0087 & -0.0167 \\
& $(0.0850)$ & $(0.0770)$ & $(0.6350)$ & $(0.9740)$ & $(0.3520)$ & $(0.3610)$ & $(0.2810)$ \\
\hline \multirow{2}{*}{$\Delta \ln Q$} & -0.0058 & $-0.0084^{*}$ & 0.0001 & 0.0014 & $0.0071^{* *}$ & 0.0060 & 0.0050 \\
& $(0.3990)$ & $(0.0940)$ & $(0.9840)$ & $(0.4120)$ & $(0.0460)$ & $(0.3390)$ & $(0.6770)$ \\
\hline
\end{tabular}

Note: *** is significant at the $1 \%$ level; ** is significant at the $5 \%$ level; * is significant at the $10 \%$ level. The number of observations is 1291 . The upper numbers are the coefficient of the quantile regression and the p-values are in the parentheses.

Table 14. Estimation Results for the Quantile Regression—Bullish Harami-holding for 3 days

\begin{tabular}{|llllllll|}
\hline Variables & $5^{\text {th }}$ & $10^{\text {th }}$ & $25^{\text {th }}$ & $50^{\text {th }}$ & $75^{\text {th }}$ & $90^{\text {th }}$ & $95^{\text {th }}$ \\
\hline \multirow{2}{*}{$\Delta$ OPEN } & $0.4285^{*}$ & 0.0470 & -0.1696 & $-0.2863^{* * *}$ & -0.1449 & -0.0399 & -0.0088 \\
& $(0.0860)$ & $(0.8120)$ & $(0.1120)$ & $(<0.0001)$ & $(0.2640)$ & $(0.8870)$ & $(0.9880)$ \\
\hline \multirow{2}{*}{$\Delta R B$} & $0.0292^{*}$ & 0.0147 & 0.0084 & 0.0018 & 0.0095 & -0.0057 & 0.0072 \\
& $(0.0780)$ & $(0.2900)$ & $(0.2180)$ & $(0.7080)$ & $(0.1590)$ & $(0.6080)$ & $(0.6920)$ \\
\hline \multirow{2}{*}{$\Delta \ln Q$} & -0.0091 & -0.0010 & 0.0005 & 0.0009 & 0.0019 & 0.0065 & 0.0124 \\
& $(0.2680)$ & $(0.8860)$ & $(0.8960)$ & $(0.7250)$ & $(0.6350)$ & $(0.3810)$ & $(0.4060)$ \\
\hline
\end{tabular}

Note: *** is significant at the $1 \%$ level; ** is significant at the $5 \%$ level; * is significant at the $10 \%$ level. The number of observations is 1291 . The upper numbers are the coefficient of the quantile regression and the p-values are in the parentheses. 
Table 15. Estimation Results for the Quantile Regression-Bullish Harami-holding for 4 days

\begin{tabular}{|llllllll|}
\hline Variables & $5^{\text {th }}$ & $10^{\text {th }}$ & $25^{\text {th }}$ & $50^{\text {th }}$ & $75^{\text {th }}$ & $90^{\text {th }}$ & $95^{\text {th }}$ \\
\hline \multirow{2}{*}{$\Delta$ OPEN } & 0.1391 & $0.3737^{*}$ & -0.1310 & $-0.3407^{* * *}$ & -0.0735 & -0.0589 & 0.0324 \\
& $(0.5840)$ & $(0.0800)$ & $(0.2620)$ & $(<0.0001)$ & $(0.6960)$ & $(0.8800)$ & $(0.9630)$ \\
\hline \multirow{2}{*}{$\Delta R B$} & 0.0066 & 0.0050 & 0.0028 & 0.0057 & 0.0086 & -0.0102 & -0.0147 \\
& $(0.7140)$ & $(0.7330)$ & $(0.7180)$ & $(0.2560)$ & $(0.3390)$ & $(0.5200)$ & $(0.5000)$ \\
\hline \multirow{2}{*}{$\Delta \ln Q$} & 0.0112 & -0.0052 & -0.0055 & -0.0005 & 0.0066 & 0.0093 & 0.0243 \\
& $(0.1890)$ & $(0.5150)$ & $(0.1670)$ & $(0.8440)$ & $(0.1920)$ & $(0.3430)$ & $(0.1310)$ \\
\hline
\end{tabular}

Note: *** is significant at the $1 \%$ level; $* *$ is significant at the $5 \%$ level; * is significant at the $10 \%$ level. The number of observations is 1291 . The upper numbers are the coefficient of the quantile regression and the p-values are in the parentheses.

Table 16. Estimation Results for the Quantile Regression—Bullish Harami- holding for 5 days

\begin{tabular}{|llllllll|}
\hline Variables & $5^{\text {th }}$ & $10^{\text {th }}$ & $25^{\text {th }}$ & $50^{\text {th }}$ & $75^{\text {th }}$ & $90^{\text {th }}$ & $95^{\text {th }}$ \\
\hline \multirow{2}{*}{$\triangle O P E N$} & 0.1056 & $0.5903^{* * *}$ & -0.0032 & -0.1415 & 0.1422 & 0.0969 & -0.1751 \\
& $(0.7190)$ & $(0.0010)$ & $(0.9860)$ & $(0.2050)$ & $(0.4380)$ & $(0.8240)$ & $(0.8210)$ \\
\hline \multirow{2}{*}{$\Delta R B$} & 0.0134 & 0.0199 & 0.0170 & 0.0020 & 0.0045 & -0.0158 & -0.0203 \\
& $(0.5400)$ & $(0.1290)$ & $(0.1480)$ & $(0.7700)$ & $(0.6040)$ & $(0.3000)$ & $(0.4290)$ \\
\hline \multirow{2}{*}{$\Delta \ln Q$} & 0.0156 & 0.0013 & $-0.0138^{* *}$ & 0.0018 & 0.0043 & 0.0145 & 0.0247 \\
& $(0.1540)$ & $(0.8540)$ & $(0.0240)$ & $(0.6210)$ & $(0.4060)$ & $(0.1650)$ & $(0.2080)$ \\
\hline
\end{tabular}

Note: $* * *$ is significant at the $1 \%$ level; ** is significant at the $5 \%$ level; * is significant at the $10 \%$ level. The number of observations is 1291 . The upper numbers are the coefficient of the quantile regression and the p-values are in the parentheses.

Table 17. Estimation Results for the Quantile Regression—Dark-Cloud Cover-holding for 1 day

\begin{tabular}{|llllllll|}
\hline Variables & $5^{\text {th }}$ & $10^{\text {th }}$ & $25^{\text {th }}$ & $50^{\text {th }}$ & $75^{\text {th }}$ & $90^{\text {th }}$ & $95^{\text {th }}$ \\
\hline \multirow{2}{*}{$\Delta$ OPEN } & $1.0641^{* *}$ & $0.7384^{* * *}$ & $0.7403^{* * *}$ & $0.7023^{* * *}$ & $0.6910^{* * *}$ & $0.5435^{* *}$ & $1.0774^{* * *}$ \\
& $(0.0160)$ & $(0.0060)$ & $(0.0060)$ & $(<0.0001)$ & $(<0.0001)$ & $(0.0320)$ & $(<0.0001)$ \\
\hline \multirow{2}{*}{$\Delta R B$} & $-0.0016^{* * *}$ & $-0.0013^{*}$ & 0.0005 & 0.0002 & -0.0001 & -0.0004 & -0.0001 \\
& $(0.0020)$ & $(0.0780)$ & $(0.3370)$ & $(0.7940)$ & $(0.8580)$ & $(0.8570)$ & $(0.5710)$ \\
\hline \multirow{2}{*}{$\Delta \ln Q$} & $-0.0326^{* *}$ & $-0.0345^{* * *}$ & $-0.0209^{* *}$ & $-0.0160^{*}$ & $-0.0144^{* *}$ & -0.0114 & $-0.0272^{* * *}$ \\
& $(0.0340)$ & $(0.0040)$ & $(0.0440)$ & $(0.0680)$ & $(0.0190)$ & $(0.4230)$ & $(<0.0001)$ \\
\hline
\end{tabular}

Note: $* * *$ is significant at the $1 \%$ level; $* *$ is significant at the $5 \%$ level; * is significant at the $10 \%$ level. The number of observations is 165 . The upper numbers are the coefficient of the quantile regression and the p-values are in the parentheses.

Table 18. Estimation Results for the Quantile Regression—Dark-Cloud Cover—holding for 2 days

\begin{tabular}{|llllllll|}
\hline Variables & $5^{\text {th }}$ & $10^{\text {th }}$ & $25^{\text {th }}$ & $50^{\text {th }}$ & $75^{\text {th }}$ & $90^{\text {th }}$ & $95^{\text {th }}$ \\
\hline \multirow{2}{*}{$\Delta$ OPEN } & 0.7482 & 0.4088 & $0.3097^{*}$ & $0.6955^{* * *}$ & $0.7509^{* * *}$ & $0.8878^{* *}$ & 0.2670 \\
& $(0.1330)$ & $(0.5300)$ & $(0.0630)$ & $(<0.0001)$ & $(<0.0001)$ & $(0.0230)$ & $(0.6300)$ \\
\hline \multirow{2}{*}{$\Delta R B$} & -0.0001 & -0.0002 & $-0.0008^{*}$ & -0.0006 & $-0.0013^{* * *}$ & $-0.0017^{* *}$ & $-0.0020^{* *}$ \\
& $(0.9400)$ & $(0.9480)$ & $(0.0960)$ & $(0.2260)$ & $(<0.0001)$ & $(0.0160)$ & $(0.0240)$ \\
\hline \multirow{2}{*}{$\Delta \ln Q$} & -0.0137 & -0.0288 & $-0.0229^{* * *}$ & -0.0106 & 0.0106 & 0.0128 & 0.0114 \\
& $(0.6730)$ & $(0.2190)$ & $(0.0070)$ & $(0.1840)$ & $(0.1350)$ & $(0.5860)$ & $(0.7940)$ \\
\hline
\end{tabular}

Note: $* *$ is significant at the $1 \%$ level; $* *$ is significant at the $5 \%$ level; * is significant at the $10 \%$ level. The number of observations is 165 . The upper numbers are the coefficient of the quantile regression and the p-values are in the parentheses.

Table 19. Estimation Results for the Quantile Regression-Dark-Cloud Cover-holding for 3 days

\begin{tabular}{|llllllll|}
\hline Variables & $5^{\text {th }}$ & $10^{\text {th }}$ & $25^{\text {th }}$ & $50^{\text {th }}$ & $75^{\text {th }}$ & $90^{\text {th }}$ & $95^{\text {th }}$ \\
\hline \multirow{2}{*}{$\Delta$ OPEN } & $1.4551^{* *}$ & 1.2318 & 0.3754 & 0.2773 & $0.5267^{* *}$ & 0.4394 & 0.5879 \\
& $(0.0270)$ & $(0.1970)$ & $(0.4410)$ & $(0.2250)$ & $(0.0160)$ & $(0.3050)$ & $(0.2020)$ \\
\hline \multirow{2}{*}{$\Delta R B$} & -0.0006 & -0.0002 & -0.0008 & $-0.0014^{* *}$ & $-0.0023^{* * *}$ & $-0.0021^{* * *}$ & $-0.0037^{* * *}$ \\
& $(0.6700)$ & $(0.9890)$ & $(0.6430)$ & $(0.0290)$ & $(<0.0001)$ & $(<0.0001)$ & $(<0.0001)$ \\
\hline \multirow{2}{*}{$\Delta \ln Q$} & -0.0230 & -0.0108 & -0.0017 & -0.0061 & -0.0019 & -0.0014 & 0.0319 \\
& $(0.5730)$ & $(0.7460)$ & $(0.9330)$ & $(0.5580)$ & $(0.8480)$ & $(0.9390)$ & $(0.1720)$ \\
\hline
\end{tabular}

Note: $* *$ is significant at the $1 \%$ level; ** is significant at the $5 \%$ level; * is significant at the $10 \%$ level. The number of observations is 165 . The upper numbers are the coefficient of the quantile regression and the p-values are in the parentheses. 
Table 20. Estimation Results for the Quantile Regression —Dark-Cloud Cover-holding for 4 days

\begin{tabular}{|llllllll|}
\hline Variables & $5^{\text {th }}$ & $10^{\text {th }}$ & $25^{\text {th }}$ & $50^{\text {th }}$ & $75^{\text {th }}$ & $90^{\text {th }}$ & $95^{\text {th }}$ \\
\hline \multirow{2}{*}{$\Delta$ OPEN } & 0.4351 & 0.7260 & 0.4164 & $0.4641^{*}$ & $0.8971^{* *}$ & 0.1996 & 0.3702 \\
& $(0.6580)$ & $(0.4170)$ & $(0.4010)$ & $(0.0540)$ & $(0.0140)$ & $(0.8330)$ & $(0.3970)$ \\
\hline \multirow{2}{*}{$\Delta R B$} & 0.0021 & 0.0008 & 0.0001 & -0.0006 & -0.0005 & -0.0023 & $-0.0035^{* * *}$ \\
& $(0.3610)$ & $(0.7260)$ & $(0.9600)$ & $(0.4020)$ & $(0.5430)$ & $(0.2390)$ & $(0.0000)$ \\
\hline \multirow{2}{*}{$\Delta \ln Q$} & 0.0150 & -0.0093 & -0.0090 & -0.0073 & -0.0179 & 0.0049 & $0.0394^{* *}$ \\
& $(0.8150)$ & $(0.7830)$ & $(0.6760)$ & $(0.5190)$ & $(0.2270)$ & $(0.8650)$ & $(0.0370)$ \\
\hline
\end{tabular}

Note: *** is significant at the $1 \%$ level; ** is significant at the $5 \%$ level; * is significant at the $10 \%$ level. The number of observations is 165 . The upper numbers are the coefficient of the quantile regression and the p-values are in the parentheses.

Table 21. Estimation Results for the Quantile Regression —Dark-Cloud Cover-holding for 5 days

\begin{tabular}{|llllllll|}
\hline Variables & $5^{\text {th }}$ & $10^{\text {th }}$ & $25^{\text {th }}$ & $50^{\text {th }}$ & $75^{\text {th }}$ & $90^{\text {th }}$ & $95^{\text {th }}$ \\
\hline \multirow{2}{*}{$\Delta$ OPEN } & 0.3593 & 0.3823 & 0.2857 & $0.7388^{* * *}$ & 0.5007 & 0.3609 & 0.4371 \\
& $(0.8070)$ & $(0.7900)$ & $(0.4570)$ & $(<0.0001)$ & $(0.2480)$ & $(0.5300)$ & $(0.4920)$ \\
\hline \multirow{2}{*}{$\Delta R B$} & 0.0010 & 0.0004 & 0.0008 & 0.0002 & -0.0005 & -0.0015 & -0.0024 \\
& $(0.7600)$ & $(0.9170)$ & $(0.5770)$ & $(0.6850)$ & $(0.5190)$ & $(0.4920)$ & $(0.4070)$ \\
\hline \multirow{2}{*}{$\Delta \ln Q$} & 0.0487 & -0.0260 & $-0.0426^{* * *}$ & -0.0126 & -0.0108 & -0.0241 & -0.0200 \\
& $(0.6210)$ & $(0.6310)$ & $(0.0070)$ & $(0.1720)$ & $(0.4570)$ & $(0.4660)$ & $(0.4620)$ \\
\hline
\end{tabular}

Note: *** is significant at the $1 \%$ level; $* *$ is significant at the $5 \%$ level; * is significant at the $10 \%$ level. The number of observations is 165 . The upper numbers are the coefficient of the quantile regression and the p-values are in the parentheses.

Table 22. Estimation Results for the Quantile Regression-Bearish Engulfing-holding for 1 day

\begin{tabular}{|llllllll|}
\hline Variables & $5^{\text {th }}$ & $10^{\text {th }}$ & $25^{\text {th }}$ & $50^{\text {th }}$ & $75^{\text {th }}$ & $90^{\text {th }}$ & $95^{\text {th }}$ \\
\hline \multirow{2}{*}{$\Delta$ OPEN } & $0.5795^{* * *}$ & $0.3263^{* * *}$ & $0.3093^{* * *}$ & $0.1392^{* * *}$ & $0.1624^{* * *}$ & 0.1648 & 0.2368 \\
& $(<0.0001)$ & $(<0.0001)$ & $(<0.0001)$ & $(<0.0001)$ & $(0.0010)$ & $(0.1640)$ & $(0.2780)$ \\
\hline \multirow{2}{*}{$\Delta R B$} & $0.0001^{* * *}$ & 0.0001 & 0.0002 & $-2.50 \mathrm{E}-06$ & -0.0003 & -0.0001 & -0.0002 \\
& $(<0.0001)$ & $(0.5000)$ & $(0.6020)$ & $(0.9360)$ & $(0.1500)$ & $(0.7790)$ & $(0.4530)$ \\
\hline \multirow{2}{*}{$\Delta \ln Q$} & $0.0090^{* *}$ & 0.0034 & 0.0002 & -0.0001 & 0.0012 & $0.0064^{*}$ & $0.0064^{*}$ \\
& $(0.0210)$ & $(0.3380)$ & $(0.9170)$ & $(0.9930)$ & $(0.5210)$ & $(0.0570)$ & $(0.0820)$ \\
\hline
\end{tabular}

Note: $* * *$ is significant at the $1 \%$ level; ** is significant at the $5 \%$ level; * is significant at the $10 \%$ level. The number of observations is 1554 . The upper numbers are the coefficient of the quantile regression and the p-values are in the parentheses.

Table 23. Estimation Results for the Quantile Regression —Bearish Engulfing — holding for 2 days

\begin{tabular}{|llllllll|}
\hline Variables & $5^{\text {th }}$ & $10^{\text {th }}$ & $25^{\text {th }}$ & $50^{\text {th }}$ & $75^{\text {th }}$ & $90^{\text {th }}$ & $95^{\text {th }}$ \\
\hline \multirow{2}{*}{$\Delta$ OPEN } & 0.1959 & $0.3030^{* *}$ & $0.4436^{* * *}$ & $0.3569^{* * *}$ & $0.1836^{* *}$ & -0.0049 & 0.0470 \\
& $(0.2460)$ & $(0.0240)$ & $(<0.0001)$ & $(<0.0001)$ & $(0.0030)$ & $(0.9680)$ & $(0.7830)$ \\
\hline \multirow{2}{*}{$\Delta R B$} & $0.0001^{* *}$ & 0.0001 & 0.0002 & $0.0001^{* *}$ & 0.0002 & -0.0001 & $-0.0001^{* * *}$ \\
& $(0.0350)$ & $(0.8110)$ & $(0.7300)$ & $(0.0310)$ & $(0.4790)$ & $(0.2060)$ & $(0.0030)$ \\
\hline \multirow{2}{*}{$\Delta \ln Q$} & 0.0096 & 0.0050 & 0.0025 & 0.0019 & 0.0010 & -0.0023 & -0.0010 \\
& $(0.1870)$ & $(0.4110)$ & $(0.3940)$ & $(0.3440)$ & $(0.6630)$ & $(0.6640)$ & $(0.8850)$ \\
\hline
\end{tabular}

Note: $* * *$ is significant at the $1 \%$ level; ** is significant at the $5 \%$ level; * is significant at the $10 \%$ level. The number of observations is 1554 . The upper numbers are the coefficient of the quantile regression and the p-values are in the parentheses.

Table 24. Estimation Results for the Quantile Regression—Bearish Engulfing—holding for 3 days

\begin{tabular}{|llllllll|}
\hline Variables & $5^{\text {th }}$ & $10^{\text {th }}$ & $25^{\text {th }}$ & $50^{\text {th }}$ & $75^{\text {th }}$ & $90^{\text {th }}$ & $95^{\text {th }}$ \\
\hline \multirow{2}{*}{$\Delta O P E N$} & $0.6209^{* * *}$ & $0.5022^{* * *}$ & $0.3237^{* * *}$ & $0.1887^{* * *}$ & -0.0322 & -0.0035 & -0.0964 \\
& $(0.0030)$ & $(0.0020)$ & $(0.0010)$ & $(0.0010)$ & $(0.6760)$ & $(0.9800)$ & $(0.7350)$ \\
\hline \multirow{2}{*}{$\Delta R B$} & 0.0002 & 0.0002 & 0.0001 & 0.0001 & $<0.0001$ & -0.0002 & 0.0001 \\
& $(0.5100)$ & $(0.6190)$ & $(0.4890)$ & $(0.3170)$ & $(0.8330)$ & $(0.7400)$ & $(0.1680)$ \\
\hline \multirow{2}{*}{$\Delta \ln Q$} & $0.0167^{*}$ & 0.0103 & -0.0003 & -0.0001 & $0.0073^{* *}$ & -0.0029 & -0.0065 \\
& $(0.0760)$ & $(0.1140)$ & $(0.9480)$ & $(0.9660)$ & $(0.0370)$ & $(0.5650)$ & $(0.5240)$ \\
\hline
\end{tabular}

Note: $* * *$ is significant at the $1 \%$ level; $* *$ is significant at the $5 \%$ level; $*$ is significant at the $10 \%$ level. The number of observations is 1554 . The upper numbers are the coefficient of the quantile regression and the p-values are in the parentheses. 
Table 25. Estimation Results for the Quantile Regression-Bearish Engulfing - holding for 4 days

\begin{tabular}{|llllllll|}
\hline Variables & $5^{\text {th }}$ & $10^{\text {th }}$ & $25^{\text {th }}$ & $50^{\text {th }}$ & $75^{\text {th }}$ & $90^{\text {th }}$ & $95^{\text {th }}$ \\
\hline \multirow{2}{*}{$\Delta$ OPEN } & $0.6908^{*}$ & $0.6701^{* * *}$ & $0.4388^{* * *}$ & $0.1640^{* *}$ & 0.0384 & $-0.3650^{*}$ & $-0.4901^{* *}$ \\
& $(0.0810)$ & $(<0.0001)$ & $(<0.0001)$ & $(0.0180)$ & $(0.6400)$ & $(0.0780)$ & $(0.0430)$ \\
\hline \multirow{2}{*}{$\Delta R B$} & 0.0002 & 0.0001 & 0.0004 & -0.0002 & -0.0001 & -0.0001 & -0.0002 \\
& $(0.6500)$ & $(0.3880)$ & $(0.6120)$ & $(0.5930)$ & $(0.7080)$ & $(0.2010)$ & $(0.1570)$ \\
\hline \multirow{2}{*}{$\Delta \ln Q$} & 0.0177 & $0.0124^{*}$ & 0.0020 & -0.0003 & 0.0059 & 0.0045 & -0.0019 \\
& $(0.2670)$ & $(0.0840)$ & $(0.6610)$ & $(0.9180)$ & $(0.1100)$ & $(0.5620)$ & $(0.8290)$ \\
\hline
\end{tabular}

Note: $* * *$ is significant at the $1 \%$ level; ** is significant at the $5 \%$ level; * is significant at the $10 \%$ level. The number of observations is 1554 . The upper numbers are the coefficient of the quantile regression and the p-values are in the parentheses.

Table 26. Estimation Results for the Quantile Regression-Bearish Engulfing-holding for 5 days

\begin{tabular}{|llllllll|}
\hline Variables & $5^{\text {th }}$ & $10^{\text {th }}$ & $25^{\text {th }}$ & $50^{\text {th }}$ & $75^{\text {th }}$ & $90^{\text {th }}$ & $95^{\text {th }}$ \\
\hline \multirow{2}{*}{$\Delta O P E N$} & $0.8843^{* *}$ & $0.6057^{* *}$ & $0.4248^{* * *}$ & $0.1270^{*}$ & -0.0706 & -0.1971 & -0.1685 \\
& $(0.0270)$ & $(0.0130)$ & $(0.0000)$ & $(0.0990)$ & $(0.5680)$ & $(0.1840)$ & $(0.6080)$ \\
\hline \multirow{2}{*}{$\Delta R B$} & $0.0003^{* * *}$ & $0.0002^{* *}$ & 0.0001 & $<0.0001$ & -0.0004 & $0.0001^{* * *}$ & 0.0002 \\
& $(0.0000)$ & $(0.0220)$ & $(0.4460)$ & $(0.9870)$ & $(0.5340)$ & $(0.0020)$ & $(0.8220)$ \\
\hline \multirow{2}{*}{$\Delta \ln Q$} & $0.0306^{* *}$ & $0.0189^{*}$ & -0.0009 & 0.0015 & 0.0026 & 0.0018 & -0.0048 \\
& $(0.0290)$ & $(0.0600)$ & $(0.8550)$ & $(0.6660)$ & $(0.6500)$ & $(0.7650)$ & $(0.7230)$ \\
\hline
\end{tabular}

Note: $* * *$ is significant at the $1 \%$ level; $* *$ is significant at the $5 \%$ level; * is significant at the $10 \%$ level. The number of observations is 1554 . The upper numbers are the coefficient of the quantile regression and the p-values are in the parentheses.

Table 27. Estimation Results for the Quantile Regression—Bearish Harami- -holding for 1 day

\begin{tabular}{|llllllll|}
\hline Variables & $5^{\text {th }}$ & $10^{\text {th }}$ & $25^{\text {th }}$ & $50^{\text {th }}$ & $75^{\text {th }}$ & $90^{\text {th }}$ & $95^{\text {th }}$ \\
\hline \multirow{2}{*}{$\Delta$ OPEN } & 0.2894 & 0.1438 & $0.1930^{* *}$ & $0.2830^{* * *}$ & $0.3515^{* * *}$ & $0.5474^{* * *}$ & $0.5488^{* * *}$ \\
& $(0.2330)$ & $(0.2520)$ & $(0.0180)$ & $(0.0000)$ & $(0.0000)$ & $(0.0000)$ & $(0.0000)$ \\
\hline \multirow{2}{*}{$\Delta R B$} & $>-0.0001^{* * *}$ & $>-0.0001^{* * *}$ & $>-0.0001^{* * *}$ & $>-0.0001$ & $<0.0001$ & $<0.0001$ & $<0.0001^{* * *}$ \\
& $(0.0000)$ & $(0.0000)$ & $(0.0000)$ & $(0.1740)$ & $(0.9320)$ & $(0.7740)$ & $(0.0000)$ \\
\hline \multirow{2}{*}{$\Delta \ln Q$} & $-0.0152^{* *}$ & $-0.0116^{* * *}$ & -0.0028 & 0.0014 & 0.0022 & $0.0106^{* * *}$ & $0.0086^{*}$ \\
& $(0.0220)$ & $(0.0040)$ & $(0.2660)$ & $(0.4280)$ & $(0.4030)$ & $(0.0080)$ & $(0.0780)$ \\
\hline
\end{tabular}

Note: $* *$ is significant at the $1 \%$ level; $* *$ is significant at the $5 \%$ level; * is significant at the $10 \%$ level. The number of observations is 882 . The upper numbers are the coefficient of the quantile regression and the p-values are in the parentheses.

Table 28. Estimation Results for the Quantile Regression-Bearish Harami-holding for 2 days

\begin{tabular}{|llllllll|}
\hline Variables & $5^{\text {th }}$ & $10^{\text {th }}$ & $25^{\text {th }}$ & $50^{\text {th }}$ & $75^{\text {th }}$ & $90^{\text {th }}$ & $95^{\text {th }}$ \\
\hline \multirow{2}{*}{$\Delta$ OPEN } & 0.0208 & -0.0514 & 0.1088 & $0.3716^{* * *}$ & $0.5900^{* * *}$ & 0.4127 & 0.4314 \\
& $(0.9690)$ & $(0.8450)$ & $(0.3630)$ & $(<0.0001)$ & $(<0.0001)$ & $(0.1200)$ & $(0.3550)$ \\
\hline \multirow{2}{*}{$\Delta R B$} & $>-0.0001^{* * *}$ & $>-0.0001^{*}$ & $>-0.0001$ & $<0.0001$ & $<0.001^{* * *}$ & $0.0001^{* * *}$ & $0.0001^{* * *}$ \\
& $(0.0010)$ & $(0.0600)$ & $(0.6080)$ & $(0.1410)$ & $(0.0010)$ & $(<0.0001)$ & $(<0.0001)$ \\
\hline \multirow{2}{*}{$\Delta \ln Q$} & $-0.0301^{* *}$ & -0.0102 & -0.0036 & 0.0007 & 0.0016 & 0.0080 & 0.0058 \\
& $(0.0240)$ & $(0.1850)$ & $(0.2540)$ & $(0.7520)$ & $(0.6720)$ & $(0.2400)$ & $(0.6470)$ \\
\hline
\end{tabular}

Note: *** is significant at the $1 \%$ level; ** is significant at the $5 \%$ level; * is significant at the $10 \%$ level. The number of observations is 882 . The upper numbers are the coefficient of the quantile regression and the p-values are in the parentheses.

Table 29. Estimation Results for the Quantile Regression-Bearish Harami- -holding for 3 days

\begin{tabular}{|llllllll|}
\hline Variables & $5^{\text {th }}$ & $10^{\text {th }}$ & $25^{\text {th }}$ & $50^{\text {th }}$ & $75^{\text {th }}$ & $90^{\text {th }}$ & $95^{\text {th }}$ \\
\hline \multirow{2}{*}{$\Delta$ OPEN } & -0.0956 & 0.2358 & 0.0457 & $0.3026^{* * *}$ & $0.5662^{* * *}$ & $0.4545^{*}$ & 0.5424 \\
& $(0.9080)$ & $(0.5680)$ & $(0.7540)$ & $(0.0060)$ & $(<0.0001)$ & $(0.0770)$ & $(0.2470)$ \\
\hline \multirow{2}{*}{$\Delta R B$} & $>-0.0001$ & $<0.0001$ & $<0.0001$ & $0.0001^{* * *}$ & $0.0001^{* * *}$ & $0.0002^{* * *}$ & $0.0002^{* * *}$ \\
& $(0.3180)$ & $(0.9700)$ & $(0.3070)$ & $(<0.0001)$ & $(<0.0001)$ & $(<0.0001)$ & $(<0.0001)$ \\
\hline \multirow{2}{*}{$\Delta \ln Q$} & -0.0193 & -0.0044 & -0.0062 & -0.0013 & 0.0024 & $0.0127^{* *}$ & 0.0003 \\
& $(0.4410)$ & $(0.7100)$ & $(0.1270)$ & $(0.7110)$ & $(0.5750)$ & $(0.0420)$ & $(0.9540)$ \\
\hline
\end{tabular}

Note: $* * *$ is significant at the $1 \%$ level; $* *$ is significant at the $5 \%$ level; * is significant at the $10 \%$ level. The number of observations is 882 . The upper numbers are the coefficient of the quantile regression and the p-values are in the parentheses. 
Table 30. Estimation Results for the Quantile Regression-Bearish Harami-holding for 4 days

\begin{tabular}{|llllllll|}
\hline Variables & $5^{\text {th }}$ & $10^{\text {th }}$ & $25^{\text {th }}$ & $50^{\text {th }}$ & $75^{\text {th }}$ & $90^{\text {th }}$ & $95^{\text {th }}$ \\
\hline \multirow{2}{*}{$\Delta$ OPEN } & -0.1921 & -0.3560 & 0.1165 & $0.3329^{*}$ & $0.5214^{* * *}$ & 0.5286 & $0.6108^{* * *}$ \\
& $(0.8500)$ & $(0.3970)$ & $(0.4430)$ & $(0.0780)$ & $(0.0010)$ & $(0.1120)$ & $(<0.0001)$ \\
\hline \multirow{2}{*}{$\Delta R B$} & $>-0.0001^{*}$ & $>-0.0001$ & $<0.0001$ & $<0.0001^{*}$ & $0.0001^{* * *}$ & $0.0002^{* * *}$ & $0.0002^{* * *}$ \\
& $(0.0650)$ & $(0.3330)$ & $(0.6380)$ & $(0.0920)$ & $(<0.0001)$ & $(<0.0001)$ & $(<0.0001)$ \\
\hline \multirow{2}{*}{$\Delta \ln Q$} & -0.0314 & -0.0187 & $-0.0083^{*}$ & -0.0035 & 0.0022 & 0.0090 & 0.0028 \\
& $(0.3180)$ & $(0.1330)$ & $(0.0770)$ & $(0.5550)$ & $(0.6390)$ & $(0.2550)$ & $(0.8180)$ \\
\hline
\end{tabular}

Note: $* * *$ is significant at the $1 \%$ level; ** is significant at the $5 \%$ level; * is significant at the $10 \%$ level. The number of observations is 882 . The upper numbers are the coefficient of the quantile regression and the p-values are in the parentheses.

Table 31. Estimation Results for the Quantile Regression-Bearish Harami-holding for 5 days

\begin{tabular}{|llllllll|}
\hline Variables & $5^{\text {th }}$ & $10^{\text {th }}$ & $25^{\text {th }}$ & $50^{\text {th }}$ & $75^{\text {th }}$ & $90^{\text {th }}$ & $95^{\text {th }}$ \\
\hline \multirow{2}{*}{$\Delta$ OPEN } & -0.0065 & -0.1969 & 0.3329 & $0.3044^{* *}$ & $0.5096^{* *}$ & 0.4863 & $0.2884^{* * *}$ \\
& $(0.9960)$ & $(0.6770)$ & $(0.1110)$ & $(0.0150)$ & $(0.0150)$ & $(0.1430)$ & $(0.0000)$ \\
\hline \multirow{2}{*}{$\Delta R B$} & -0.0001 & $>-0.0001$ & $<0.0001$ & $0.0001^{* *}$ & $0.0001^{* * *}$ & $0.0002^{* * *}$ & $0.0002^{* * *}$ \\
& $(0.1060)$ & $(0.8500)$ & $(0.7750)$ & $(0.0190)$ & $(<0.0001)$ & $(<0.0001)$ & $(<0.0001)$ \\
\hline \multirow{2}{*}{$\Delta \ln Q$} & -0.0298 & -0.0189 & $-0.0137^{* *}$ & $-0.0069^{*}$ & 0.0023 & 0.0004 & 0.0037 \\
& $(0.4700)$ & $(0.1260)$ & $(0.0310)$ & $(0.0830)$ & $(0.6940)$ & $(0.9960)$ & $(0.8090)$ \\
\hline
\end{tabular}

Note: *** is significant at the $1 \%$ level; ** is significant at the $5 \%$ level; * is significant at the $10 \%$ level. The number of observations is 882 . The upper numbers are the coefficient of the quantile regression and the p-values are in the parentheses.

\begin{tabular}{|c|c|l|}
\hline Pattern & \multicolumn{1}{|c|}{ Definition } \\
\hline Piercing & $\begin{array}{l}\text { In a downtrend, following a black line the } \\
\text { market opens lower, but closes above the } \\
\text { mid-point of the prior candlestick's real } \\
\text { body. }\end{array}$ \\
\hline Bullish Engulfing & $\begin{array}{l}\text { In a downtrend, following a black line the } \\
\text { market opens lower, but closes above the } \\
\text { open of the prior candlestick's real body. }\end{array}$ \\
\hline Bullish Harami & $\begin{array}{l}\text { In a downtrend, following a long black line } \\
\text { the market opens higher than the prior close, } \\
\text { and closes below the prior open. The second } \\
\text { day's small real body holds within the prior } \\
\text { long real body. }\end{array}$ \\
\hline
\end{tabular}

Figure 1. Two-day bullish reversal patterns

\begin{tabular}{|c|c|l|}
\hline Pattern & \multicolumn{1}{|c|}{ Chart Definition } \\
\hline Dark-Cloud Cover & $\begin{array}{l}\text { In an uptrend, following a white line the } \\
\text { market opens higher, but closes blow the } \\
\text { mid-point of the prior candlestick's real } \\
\text { body. }\end{array}$ \\
\hline Bearish Engulfing & $\begin{array}{l}\text { In an uptrend, following a white line the } \\
\text { market opens higher, but closes below the } \\
\text { open of the prior candlestick's real body. }\end{array}$ \\
\hline Bearish Harami & $\begin{array}{l}\text { In an uptrend, following a long white line } \\
\text { the market opens lower than the prior close, } \\
\text { and closes above the prior open. The second } \\
\text { day's small real body holds within the prior } \\
\text { long real body. }\end{array}$ \\
\hline
\end{tabular}

Figure 2. Two-day bearish reversal patterns 